\title{
Mass recruitment of Ophiothrix fragilis (Ophiuroidea) on sponges: settlement patterns and post-settlement dynamics
}

\author{
Xavier Turon ${ }^{1, *}$, Meritxell Codina ${ }^{1}$, Isabel Tarjuelo ${ }^{1}$, María J. Uriz ${ }^{2}$, \\ Mikel A. Becerro ${ }^{2}$ \\ ${ }^{1}$ Department of Animal Biology (Invertebrates), Faculty of Biology, University of Barcelona, 645 Diagonal Avenue, \\ 08028 Barcelona, Spain \\ ${ }^{2}$ Centre d'Estudis Avançats (CSIC), Camí de Sta. Bàrbara s/n, 17300 Blanes (Girona), Spain
}

\begin{abstract}
The main recruitment of Ophiothrix fragilis occurs in the northwestern Mediterranean in late spring-early summer. Recruits are whitish and aggregate visibly on the surfaces of some sponge species, where they can reach densities above 50 ind $\mathrm{cm}^{-2}$. In order to investigate this association, we monitored larval abundances in the plankton, and recruit distribution and dynamics on the benthos. Settlement took place in several batches, with peak abundance of recruits on sponges in June. The mean diameter of juveniles was $0.2 \mathrm{~mm}$ in June and grew to $0.4 \mathrm{~mm}$ in September. In July, after the settlement ceased, juveniles were more abundant on the surfaces of the sponges Crambe crambe, Scopalina lophyropoda and Dysidea avara (14 to 20 ind $\mathrm{cm}^{-2}$ ) than on the adjacent algal turf (4 ind. $\mathrm{cm}^{-2}$ ). No preference could be substantiated for 6 other encrusting sponge species. In contrast, juveniles were not significantly more abundant on these 3 sponges in June while settlement was under way. Recruitment on experimental sponges covered with plastic lids was reduced by two-thirds, indicating an initial colonization directly from the water column. However, clearing experiments demonstrated the ability of the young brittle stars to recolonise sponges, and brittle stars were more abundant at the periphery than at the centre of the sponges. These results indicate that brittle star recruits can select their substrata, possibly as a result of post-settlement lateral migration, resulting in an uneven distribution among sponge species. We set forth the hypothesis that this association between brittle stars and sponges is based on a trophic relationship, small brittle stars taking advantage of the inhalant currents of the sponge. In sponges with well-defined inhalant fields, almost all recruits concentrate on them, with arms flat against the sponge. When the brittle stars grow to a size above $1 \mathrm{~mm}$ (disk diameter) they abandon sponge surfaces and hide in small crevices between algae and invertebrates.
\end{abstract}

KEY WORDS: Ophiothrix · Ophiuroidea $\cdot$ Recruitment $\cdot$ Settlement $\cdot$ Association $\cdot$ Sponges

\section{INTRODUCTION}

The recruitment of benthic invertebrates involves 3 main components: larval supply, settlement, and survival of juveniles (Cameron \& Schroeter 1980, Harrold et al. 1991). The mortality associated with settlement and early post-settlement is usually very high (Rumrill 1990, Gosselin \& Qian 1997) and, therefore, these early stages of benthic life are subject to strong selective

\footnotetext{
•E-mail: xaviert@bio.ub.es
}

pressures favouring any adaptation that improves survival. Hence, multiple mechanisms of substrate selection have developed (Keough \& Downes 1982, Butman 1987. Chia 1989), which increase the chances that juveniles will find suitable places in which to thrive. Recruitment is often enhanced or inhibited by the presence of other members of the epifauna, through chemical or physical cues or simply by changes in the water flow close to the substrate (Butman et al. 1988, Pawlik 1992, Osman \& Whitlatch 1995, Abelson \& Denny 1997). Mechanisms of induction are more likely in species which rely on associations with other organ- 
isms, such as epibionts and their basibionts, predators and their prey, or parasites and hosts. Such processes acting at early stages of the benthic phase are often bottlenecks of the dynamics of invertebrate species (López et al. 1998), but few studies deal with the early post-settlement dynamics of benthic epifauna.

Adult ophiuroids are known to associate with other members of the epifauna (e.g. sea urchins: Schoppe \& Werding 1996; crinoids: Keegan 1974; hard corals: Sloan 1982; black corals: Stewart \& Mladenov 1997; sponges: Hendler 1984, Koukouras et al. 1996, Kunzmann 1996), as well as with conspecifics (reviewed in Warner 1979, Hendler 1991). Inter- and intraspecific associations are particularly common in members of the family Ophiothricidae (Zavodnik 1976, Hendler 1984), which are mainly suspension-feeders, although they can also act as deposit- or carrion-feeders (Nagabhushanam \& Colman 1959, Warner \& Woodley 1975, Warner 1982). The Ophiothricidae are also remarkable for their aggregation behaviour which leads to the formation of dense Ophiothrix beds (Guille 1964, Warner 1971, Davoult et al. 1990). All the instances above, however, involve adult individuals, and the processes leading to the associations are largely unknown. In particular, it remains unclear whether brittle stars can detect and settle selectively on particular substrata or whether the patterns found result from post-settlement processes.

Observations on ophiuroid recruitment are scant and mostly anecdotal, but juvenile brittle stars have been reported to associate with a variety of substrata (e.g. algae: Hendler \& Littman 1986; Alcyonacea: Patent 1970; hard corals: Sloan 1982, Hendler \& Littman 1986; sponges: Zavođnik 1976, Hendler 1984, Koukouras et al. 1996). Association with adult conspecifics is also common (Guille 1964, Warner 1971, Hendler 1991, McClintock et al. 1993). Recently, Hendler et al. (1999b) reported the association of juvenile brittle stars with adults of other ophiuroid species. These aggregations of juveniles in 'nursery grounds' or 'refuge substrata' do not imply an association of the corresponding adults with the same substrata, as shifts in the habitat of young brittle stars as they grow larger have been suggested or demonstrated in several instances (Guille 1964, Patent 1970, Warner 1971, Sloan 1982, Hendler \& Littman 1986, Davoult et al. 1990, Stewart \& Mladenov 1997).

In the northwestern Mediterranean, we have observed the arrival of juvenile ophiuroids at high densities in late spring-early summer. These whitish juveniles, identified as Ophiothrix fragilis, are visible on the surfaces of some encrusting sponges for several weeks. In contrast, adult individuals of this species have a cryptic mode of life in this area, hiding in crevices and under boulders (authors' pers. obs.). This phenomenon poses a strong case for selective recruitment. An association with sponges could benefit brittle star recruits by decreasing predatory risk and/or increasing food availability. A trophic benefit could result from the brittle stars taking advantage of the currents generated by sponges to increase the rates of particle capture. On the other hand, because sponges are usually chemically defended and suffer low levels of predation (McClintock 1987, Pawlik et al, 1995), brittle star recruits living on sponges could experience less predation than those living on other substrata (associational defence, Wahl \& Hay 1995).

Here we studied the association of juvenile Ophiothrix fragilis with sponges. We examined the recruitment dynamics of $O$. fragilis (number, timing and intensity of recruitment episodes, coupling between plankton and benthos). We.also studied the juvenile distribution of this species to look for preferential associations and analysed potential processes leading to such associations. Our goal was to assess the dynamics of the early benthic phase of the life history of O. fragilis and the role that the association with encrusting sponges may play in these dynamics.

\section{MATERIAL AND METHODS}

The study was conducted at Blanes (NE of Spain, western Mediterranean, $41^{\circ} 40.4^{\prime} \mathrm{N}, 2^{\circ} 48.2^{\prime} \mathrm{E}$ ). Adult individuals of Ophiothrix fragilis are common in the rocky shores of this area. They are always found scattered, hiding in crevices and, especially, under small boulders (authors' pers. obs.). They do not form the dense associations described for other zones and referred to as Ophiothrix beds (e.g. Atlantic: Warner 1971, Davoult \& Gounin 1995; Mediterranean: Guille 1964).

Plankton samples were collected in the middle of the Bay of Blanes by oblique hauls (from 10 to $0.5 \mathrm{~m}$ depth) made with a Juday-Bogorov net in a zone in which the bottom was approximately at a depth of $15 \mathrm{~m}$ and the distance to the shore was ca $500 \mathrm{~m}$. The net had a mesh size of $250 \mu \mathrm{m}$, and a circular aperture of $0.5 \mathrm{~m}$ in diameter. The samples were intended for a study of the zooplankton of the area, and the mesh size was selected in order to efficiently capture diverse groups of meroplanktonic organisms, echinoderms among them (Andreu \& Duarte 1996). The net was trawled for $2 \mathrm{~min}$ at low speed, and the volume of water filtered (usually about $100 \mathrm{~m}^{3}$ haul $^{-1}$ ) was recorded by a calibrated flow-meter. The plankton samples were fixed in formalin, and whole samples or an aliquot of them (depending on the abundance of zooplankton) were examined under a stereomicroscope. Ophiuroid larvae in the plankton samples were identified following the keys of 
Tortonese (1965) and Mortensen (1977). The numbers of plutei, plutei with rudiment, and postlarvae of Ophiothrix fragilis were recorded and transformed to abundance in ind. $\mathrm{m}^{-3}$. The plankton sampling was performed weekly from October 1996 to October 1997.

The benthic survey was performed during the recruitment seasons of 1997 and 1999 on the rocky northern shore of the Bay of Blanes. The study area consisted of vertical and subvertical rocky walls lying on a sandy bottom. Horizontal surfaces were scarce in the area, and almost devoid of encrusting sponges, so they were not studied here. For the sampling we selected walls at the same depth $(8$ to $12 \mathrm{~m})$ and orientation (north-facing). A sciaphilous assemblage was found to develop on them, mainly composed of large members of the macrobenthos (particularly encrusting sponges) interspersed with a complex of turfing and filamentous algae. These algae, mixed with hydroids, bryozoans and other invertebrates, formed a carpet 1 to $4 \mathrm{~cm}$ thick, occupying most of the space left by the large sponges. Hereafter, we will refer to this complex as the 'algal turf'. A quantitative description of this kind of community is given in Turon et al. (1996). To compare abundance between sponges and the turf community, we sampled, from 2 to 15 July 1997, the newly recruited brittle stars on the surfaces of the 9 dominant encrusting sponges in this area. The species studied were: Crambe crambe, Scopalina lophyropoda, Dysidea avara, Chondrosia reniformis, Phorbas tenacior, Pleraplysilla spinifera, Petrosia ficiformis, Hemimycale columella and Corticium candelabrum. The samples were taken following a paired design: sponge specimens were haphazardly chosen, and an area of $20 \mathrm{~cm}^{2}$ was delimited on their surfaces using a plastic Petri dish. The sponge portion under this area was then cut out and placed underwater in a plastic bag. Similarly, an area of $20 \mathrm{~cm}^{2}$ was marked on the algal turf adjacent to the sponge and closest to the area where the sponge had been sampled, and the turf within this area was scraped off and placed in a plastic bag. Using this method, we collected paired samples of sponge-turf for 9 sponge species, with at least 5 replicates each. Samples were taken to the laboratory and thoroughly rinsed in water. The water was then filtered through a $200 \mu \mathrm{m}$ mesh and the brittle stars were collected from the filter and counted. The rinsed samples were examined under a stereomicroscope to ensure that no brittle stars remained on them. The number of brittle stars was transformed to abundance $\mathrm{cm}^{-2}$ and compared between sponges and turf by paired-sample $t$-tests.

A second survey was made using the same method on 23 June 1999 some days after the peak of larval abundance, as ascertained by a parallel study of the epibenthic plankton collected with small nets towed by scuba divers a few $\mathrm{cm}$ over the rocky substrata (S.
Mariani pers. comm.). In this second survey, only the 3 sponge species which had shown a significant positive association with juvenile brittle stars in the 1997 sampling were included (5 replicates each). The rationale behind this study was to compare the pattern found after settlement had ceased (July 1997 survey) with that found while settlement was still under way (June 1999 survey).

To study the size-frequency distribution of the recruits, we took samples from mid-June to October 1997 on the surfaces of haphazardly selected specimens of the red encrusting sponge Crambe crambe, one of the landscape-dominant forms (Turon et al. 1996), on which juvenile brittle stars were clearly visible. After this date there were almost no brittle stars on this or other sponges, so we discontinued the monitoring. The samples were collected with $100 \mathrm{ml}$ plastic syringes, by sucking the recruits from the sponge surfaces. The brittle stars adhered to the surfaces, so the most efficient way to collect them involved dislodging them first with the point of the syringe and then sucking them up. Samples were collected from not less than 5 different sponges. The disk diameter of the first 150 individuals in the samples was measured in the laboratory to the nearest $0.05 \mathrm{~mm}$ with a stereomicroscope equipped with a calibrated eyepiece, and size frequency histograms were constructed. To study the time course of the abundance of juveniles on the sponges, 5 specimens of $C$. crambe and 5 specimens of the sponge Chondrosia reniformis were monitored by taking photographs with an underwater camera and close-up lens from 16 June to 9 September 1997 at intervals of approximately $10 \mathrm{~d}$.

We studied the distribution of the recruits on the sponge surfaces in large specimens of Crambe crambe by taking close-up photographs of the surfaces of 7 large (more than $600 \mathrm{~cm}^{2}$ in surface area) individuals on 2 July 1997. In C. crambe, each system of osculum plus exhalant canals covers an area of a few $\mathrm{cm}^{2}$ with the inhalant pores distributed uniformly in the spaces between the canals. These systems or units of the aquiferous system are spaced out evenly across the sponge surfaces, so that differences in recruit distribution could not stem from differences in the distribution of the inhalant and exhalant areas. Three photographs were taken from the periphery, the centre, and the intermediate zone of each sponge to give a total of 9 pictures per sponge. The density of brittle stars was estimated for each picture, and the data were analysed by a 2-way ANOVA, with the main factors being specimen (random) and zone (fixed). A second series of close-up pictures was taken of one of the species studied, which had discrete inhalant fields (Phorbas tenacior). Five individuals were photographed, and the number of brittle stars lying on the inhalant fields and 
outside them was counted. The images were then digitized and the relative surface of the inhalant fields was quantified.

To study the process of sponge colonization, we selected 18 medium-sized specimens of Crambe crambe. These sponges were photographed and their outlines were digitized for area measurements. We then placed a squared, transparent plastic fence $(8.3 \mathrm{~cm}$ wide and $2.5 \mathrm{~cm}$ high) around 6 of these sponges. The fences were glued to the rocky substrata with 2-component putty. Six more sponges were 'roofed' with a rectangle $(13.5 \times 9.6 \mathrm{~cm})$ of transparent plastic placed parallel to the substrate $3 \mathrm{~cm}$ above the sponges. The plastic pieces had legs at each corner, which were fixed to the wall with putty. The 6 remaining sponges were left untouched as a control. We assume that neither the fences nor the lids had an effect on the sponges, judging from the fact that the sponges looked healthy and were filtering actively with the oscula open during the whole experiment ( $40 \mathrm{~d}$ ). Just before the main period of settlement, on 17 June, the few juvenile brittle stars present on the 18 sponges were gently sucked out. Ten days later (27 June), we counted the settlers present on the sponge surfaces and compared them between treatments (ANOVA). During July, once the main larval arrival period was over judging from the almost complete absence of postlarvae in the plankton), the sponges were cleared of brit-

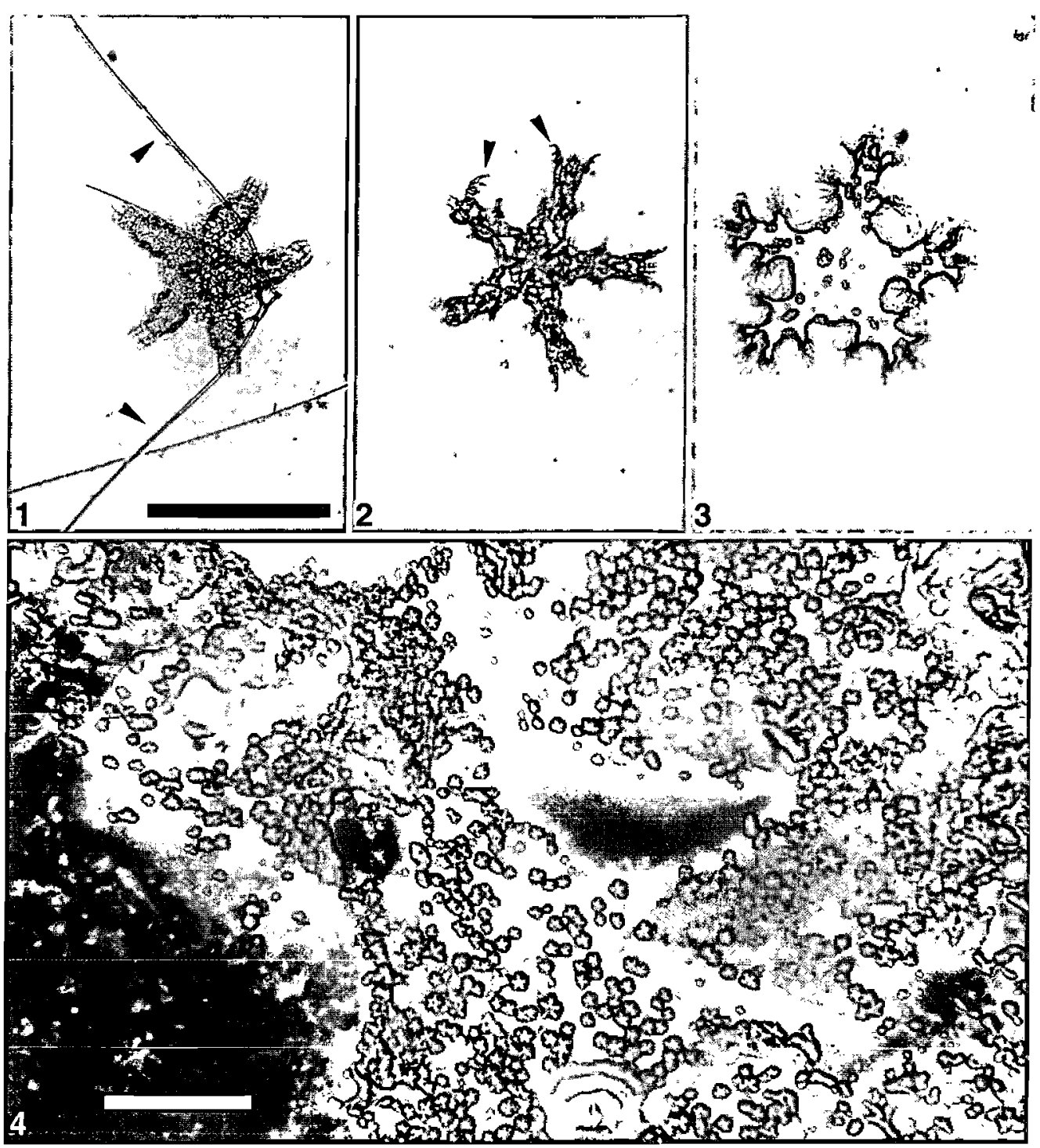

Figs. 1-4. Ophiothrix fragilis. Fig. 1. Metamorphic larva with postero-dorsal arms still present (arrowheads). Scale bar: $500 \mu \mathrm{m}$. Fig. 2. A planktonic postlarva (arrowheads: hooked arm spines). Same scale as in Fig. 1. Fig. 3. Newly settled juvenile. Same scale as in Fig. 1. Fig. 4. Surface of a specimen of Crambe crambe with recruits of $O$. fragilis on it. Scale bar: $1 \mathrm{~cm}$ 
tle stars each week, the number of juveniles present on each sponge was counted at the following weekly observation, and a percentage of recolonization was calculated for each sponge. These percentages were then compared by a 2-way repeated measures analysis (ANOVAR) with time as the within-subject factor and treatment (control, fences, roofs) as the between-subject factor. The purpose of this experiment was to assess the capacity of brittle stars to colonise substrata from the plankton (first experiment, June), and from the benthos (second experiment, July).

In all statistical analyses, the assumptions of normality (Kolmogorov-Smirnov test) and heteroscedasticity (Levene test) were tested before applying parametric analyses; if these were not met, non-parametric analogues were used. For the ANOVAR, we tested the circularity assumption by means of Mauchly's sphericity test (Von Ende 1993).

\section{RESULTS}

The plutei of Ophiothrix fragilis appeared to metamorphose while in the water column in the Bay of Blanes. All stages, from plutei to plutei with welldeveloped rudiment, could be observed in the plankton samples. In the most advanced states, all that remained of the plutei were the long posterolateral arms, while the larval body was entirely transformed into a young brittle star. Metamorphosed individuals, already free of larval arms (postlarvae in the sense of Fenaux \& Pedrotti 1988), were often observed in the plankton and were much like benthic juveniles. Figs. 1 to 4 illustrate some of these stages. The results obtained from the plankton sampling are presented in Fig. 5 as monthly mean abundances of plutei and postlarvae of $O$. fragilis. Ophioplutei peaked in our samples from April to July, with a second peak in September, and scattered individuals were found in October, December, and January. Ophioplutei densities were always less than 5 ind. $\mathrm{m}^{-3}$. In contrast, there was a high abundance of postlarvae, with a distinct peak in June (mean density $>80$ postlarvae $\mathrm{m}^{-3}$ ) and few individuals in May, July, August, and September.

If we compare the timing of the abundance of postlarvae in the plankton with the abundance of recruits on the benthos, a close temporal coupling between plankton and benthos emerges. Fig. 6 depicts the abundance of postlarvae in all plankton samples between May and July. It also shows the abundance of juvenile brittle stars in 6 specimens of Crambe crambe surveyed from 17 June and cleared of recruits at each observation time (i.e. the sponges from the fence treatment, see below). The peak abundance of postlarvae (close to 120 ind. $\mathrm{m}^{-3}$ ) was observed on 18 June, while

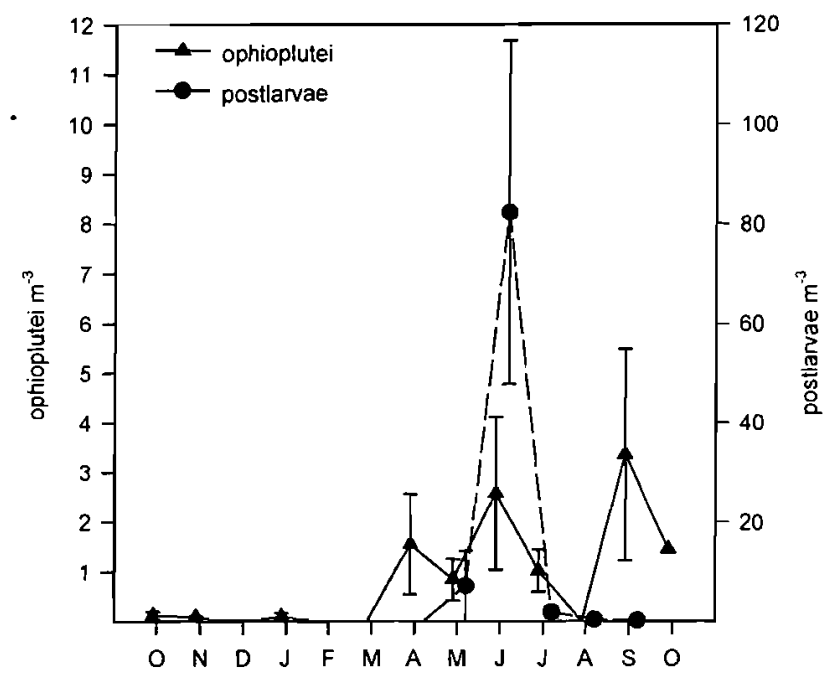

Fig. 5. Abundance of ophioplutei and postlarvae of Ophiothrix fragilis in the plankton samples from October 1996 to October 1997. Bars are standard errors

the peak abundance of recruits (ca 35 ind. $\mathrm{cm}^{-2}$ ) was observed on the sponges some days later, on 27 June. The sharp decrease in postlarvae in the plankton afterwards (July) was mirrored by a decrease in the abundance of recruits arriving during the same period.

Results of recruit counts over different sponge species performed during the first half of July showed clear interspecific patterns (Fig. 7). Brittle stars were significantly more abundant on the sponge surfaces (paired $t$-test or Wilcoxon test) with respect to the adja-

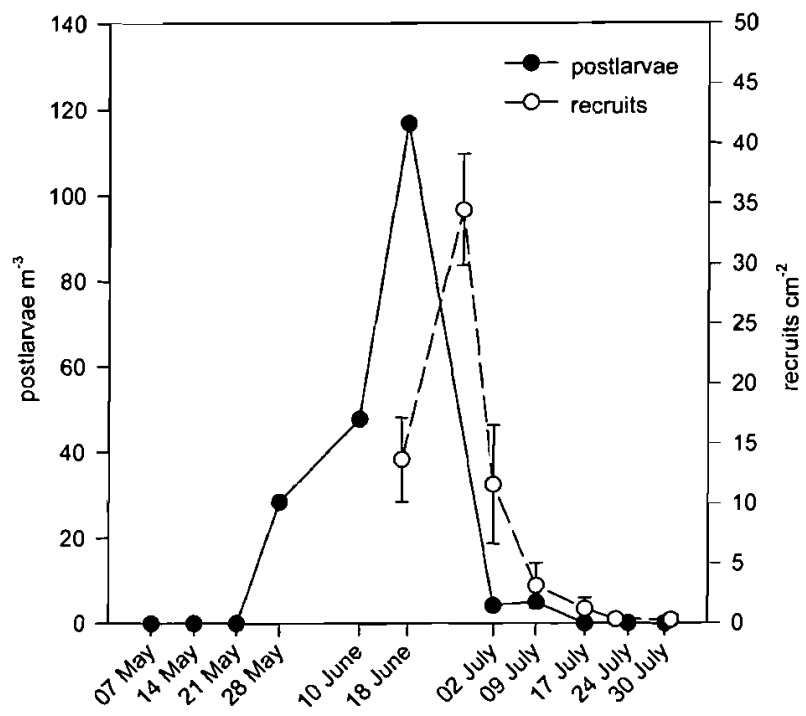

Fig. 6. Ophiothrix fragilis. Abundance of postlarvae in the plankton and of recruits on 6 Crambe crambe specimens during the samplings of May to July 1997. Bars (on recruit values only) are standard errors 


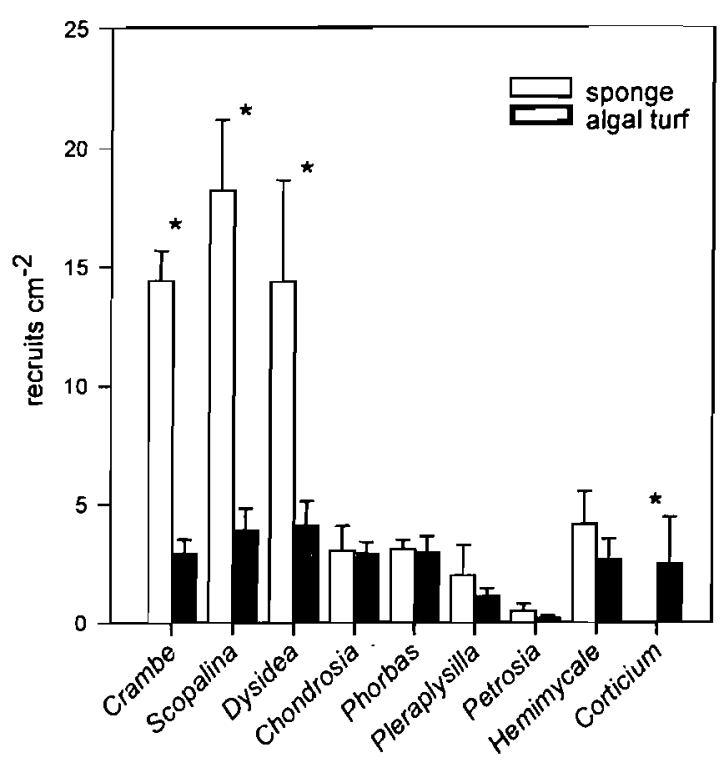

Fig. 7. July 1997: Abundance of Ophiothrix fragilis recruits on the surfaces of specimens of the 9 sponge species studied and on the algal turf adjacent to them. Asterisks denote significant abundance differences between sponge and turf. Bars are standard errors

cent algal turf in only 3 species: Crambe crambe, Scopalina lophyropoda, and Dysidea avara. In contrast, in Chondrosia reniformis, Phorbas tenacior, Pleraplysilla spinifera, Petrosia ficiformis and Hemimycale columella there were no significant differences between sponges and turf. In the case of Corticium candelabrum, significantly fewer brittle stars were found on the sponges than on the adjacent turf (in fact, only 1 specimen was found on the surface of this sponge). Overall, densities on the preferred sponges were of the order of 10 to 20 brittle stars $\mathrm{cm}^{-2}$, with high interspecimen variability (some sponges reached up to 50 brittle stars $\mathrm{cm}^{-2}$ ). Densities on non-preferred sponges or on the algal turf were usually below 5 brittle stars $\mathrm{cm}^{-2}$.

In the survey performed in 1999, during the period of larval arrival (23 June), only the 3 species that showed a clear positive relationship with juvenile brittle stars in the 1997 study (Crambe crambe, Scopalina lophyropoda and Dysidea avara) were studied. Five specimens of each species and the corresponding algal turf were sampled. The results are shown in Fig. 8. Even though there were more juvenile Ophiothrix fragilis on these 3 sponges than on the adjacent algal turf, the differences were not statistically significant at this stage (paired $t$-test, $\mathrm{p}=0.090$ for $C$. crambe, $\mathrm{p}=0.055$ for $S$. lophyropoda and $\mathrm{p}=0.075$ for $D$. avara). Note the much lower densities obtained with respect to 1997 . which could have been due to the fact that the recruitment was not finished.

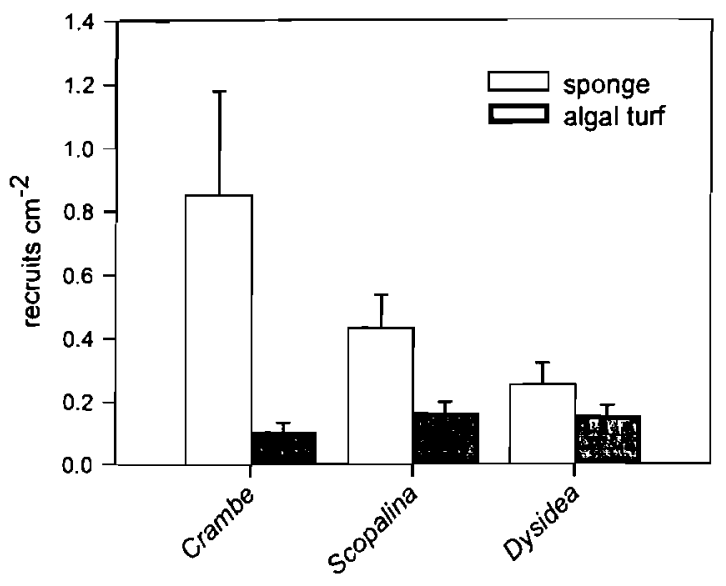

Fig. 8. June 1999: Abundance of Ophiothrix fragilis recruits on the surfaces of specimens $(n=5)$ of the 3 sponge species that had significantly higher numbers of brittle stars on them than on the adjacent algal turf in July 1997. Bars are standard errors

The size frequency histograms corresponding to the recruits collected on Crambe crambe surfaces (in 1997) are presented in Fig. 9. Recruits of the smallest size classes considered $(0.15$ and $0.2 \mathrm{~mm}$, disk diameter) were present only from mid-June to mid-July. The cohort grew in size afterwards, but it should be noted that some small individuals (in the range of 0.25 to $0.35 \mathrm{~mm}$ in diameter) were found right up to the last sampling date in October. The size distributions from the second half of July onwards, therefore, show a wide range, up to $1 \mathrm{~mm}$ in diameter, and greater (some specimens $1.25 \mathrm{~mm}$ in disk diameter were recorded in October). At the same time, there was a parallel decrease in the abundance of juveniles on the sponges. The time course of the density of recruits on the 5 specimens of $C$. crambe and Chondrosia reniformis monitored during this period is presented in Fig. 10. The values peaked at the end of June-beginning of July, and during the peak period were higher on C. crambe (one of the preferred species) than on C. reniformis (a non-preferred species). The numbers decreased sharply during July, and in August-September abundance was very low, and no differences were found between both species of sponge. The instantaneous 'decrease rates' from the peak time to September were 0.157 for C. crambe and 0.096 for C. reniformis (on a daily basis). We use the term 'decrease rates' because we could not distinguish mortality from migration to other substrata. After October, it was almost impossible to find brittle stars on the sponge surfaces, but we observed larger brittle stars associated with the sponges, not on their surfaces, but hiding in small interstices, empty barnacle caparaces, or the adjacent algal turf, and projecting their arms flat on the sponge 


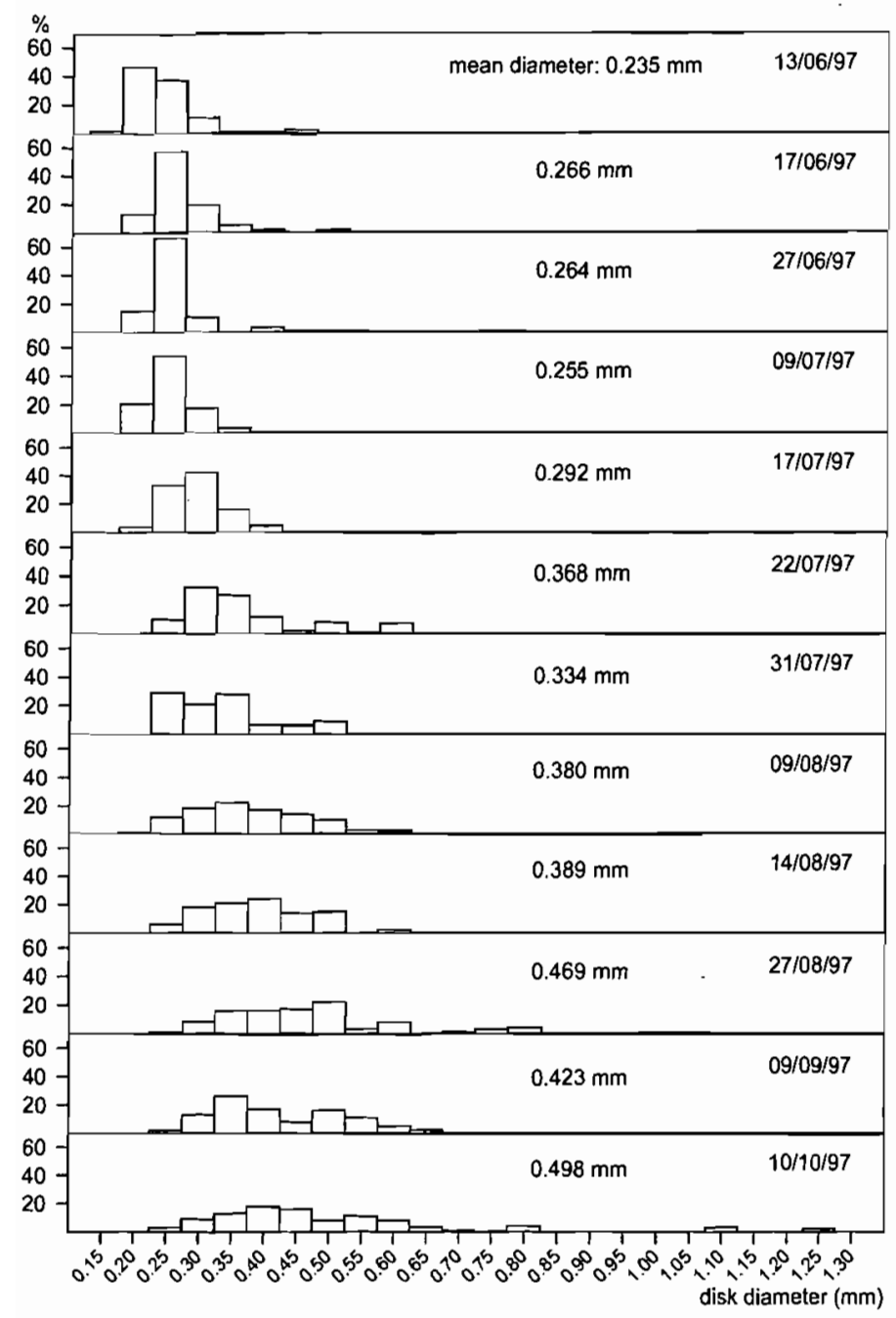

Fig. 9. Disk diameter distributions of Ophiothrix fragilis recruits found on Crambe crambe surfaces during the study period. Data are given in percentages and correspond to the measures of 150 individuals. The mean diameter of the sample is also indicated

surfaces. These brittle stars, however, were no bigger than about $4 \mathrm{~mm}$ in disk diameter. The largest specimens of Ophiothrix fragilis (up to $10-12 \mathrm{~mm}$ in disk diameter) are always found in this area hiding under rocks and boulders (authors' pers. obs.). In November 1997, we collected and measured specimens $(n=25)$ from interstices adjacent to sponge surfaces, on which they projected their arms, and specimens $(n=15)$ under boulders. Their disk diameters are plotted in Fig. 11, together with the diameters of postlarvae and the mean diameters of the recruits used to construct the size frequency histograms. Recruitment was assessed at a very early post-settlement stage, as the diameters of the recruits at the first sampling date were equivalent to the diameters of postlarvae in the plankton. There was an increase in size of the recruits after-

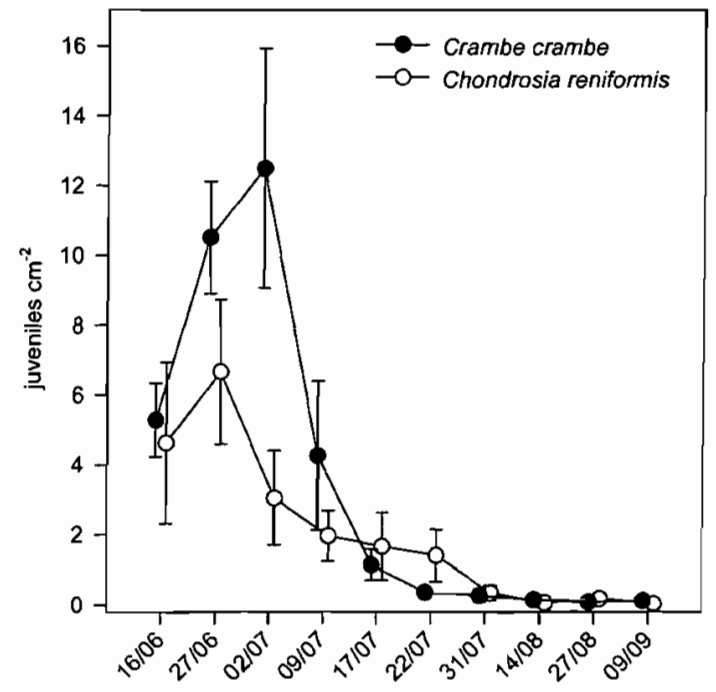

Fig. 10. Time course of the abundances of Ophiothrix fragilis juveniles on Crambe crambe and of Chondrosia reniformis (means of 5 sponge specimens of each species). Bars are standard errors

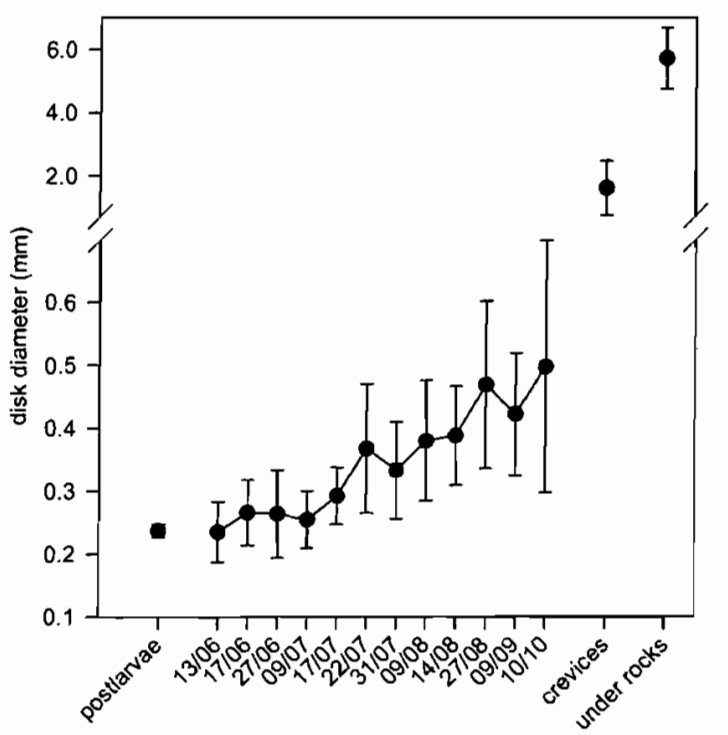

Fig. 11. Ophiothrix fragilis. Mean disk diameter of postlarvae in the plankton, of juveniles on Crambe crambe in the months following peak recruitment, of specimens found in crevices and interstices adjacent to sponge surfaces, and of specimens under boulders on the bottom. Bars are standard errors

wards, reaching a maximum mean disk diameter of ca $0.5 \mathrm{~mm}$ (October). The brittle stars on interstices adjacent to sponges had a mean diameter of about $2 \mathrm{~mm}$, while those under rocks were around $6 \mathrm{~mm}$.

The distribution of recruits on the sponge surfaces, as assessed in 7 large Crambe crambe specimens photographed on 2 July, showed a higher abundance 


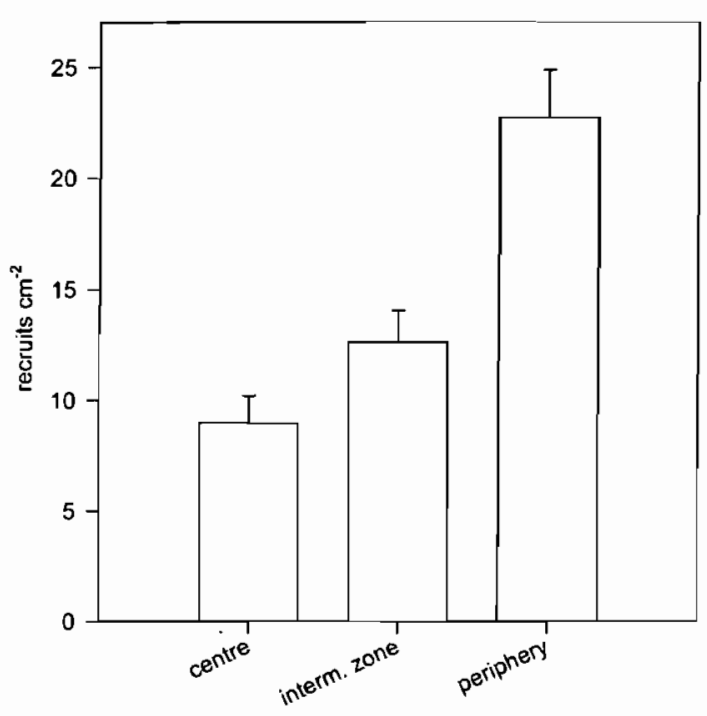

Fig. 12. Abundance of Ophiothrix fragilis recruits in the centre, intermediate zone and periphery of the surfaces of 7 large Crambe crambe specimens. Bars are standard errors

of recruits at the periphery than at the central surfaces of the sponges (Fig. 12), with intermediate values for the middle zone between the two. A 2-way ANOVA on the abundance values showed that the pattern was significantly non-random (factor zone, $p<0.001$ ), and that it did not differ among sponges (non-significant specimen factor, $p=0.755$, and interaction, $p=0.10$ ). Pairwise SNK tests revealed that the number of brittle stars was significantly greater $(p<0.05)$ at the periphery than at the centre or in the intermediate zone of the sponges. As for the study of the surfaces of a species with discrete inhalant fields (Phorbas tenacior), $88.2 \pm 6.98 \%$ (mean $\pm \mathrm{SE}$ ) of the brittle stars were found on the inhalant fields of the sponge, even though they represented only $15.08 \pm 5.57 \%$ of the sponge surface.

The effect of fences and roofs on recruitment is shown in Fig. 13. The sponges were cleared of juveniles on 17 June, at the beginning of the peak arrival of recruits, and the abundance of recruits was recorded on 27 June. There was a marked decrease in recruitment on the sponges covered by a plastic roof with respect to control or fenced sponges (ANOVA, $p=$ 0.01). Pairwise SNK tests revealed significant differences between roofs and both control and fenced sponges, with the latter two being not significantly different from each other. The results of the weekly removal of recruits from the sponges during July (Fig. 13) were not conclusive. Although we found lower percentages of recolonization for fenced sponges than for roofed or control sponges, the variances were high among sponges, and the resulting pattern was not

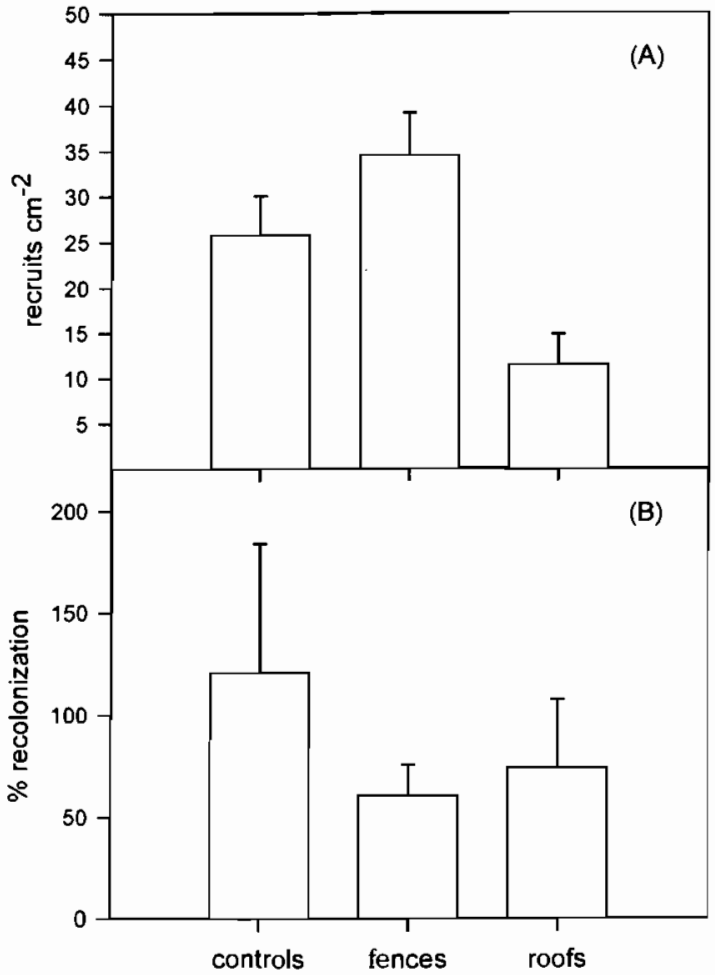

Fig. 13. (A) Abundance of Ophiothrix fragilis recruits on 2 July on 18 Crambe crambe specimens that had been cleared of ophiuroids on 27 June. The sponges were randomly assigned to the different treatments ( 6 sponges each). (B) Percentage of recolonization on the same sponges were obtained by averaging values obtained weekly during July. Bars are standard errors

significant (ANOVAR, treatment factor, $\mathrm{p}=0.568$ ). The time factor (i.e. the $4 \mathrm{wk}$ analysed), as well as the interaction between time and treatment were also non-significant ( $p=0.498$ and $p=0.333$, respectively).

\section{DISCUSSION}

It is well known that the onset of metamorphosis of some ophiuroids occurs while they are still in the water column. However, in species with long posterolateral arms, these arms are often retained by the metamorphic individual as a flotation and swimming device (Hendler 1991, and references therein). It is not clearly established whether these arms are normally resorbed before or after attachment of the juveniles by their podia (Strathmann 1978, Turner \& Miller 1988), although totally metamorphosed individuals without vestiges of the larval structures can be found in midwater plankton (Mladenov 1979). This is of importance for recruitment studies, as the posterolateral arms confer some swimming ability to such almost-metamor- 
phosed individuals and, consequently, some capability for substratum selection that would be lacking in fully metamorphic postlarvae without swimming devices, which probably sink passively to the bottom.

Our observations indicate that Ophiothrix fragilis preferentially loses its posterolateral arms while in the plankton, and this was supported by the high numbers of postlarvae found without arms. Had the arms been lost during sample processing, we should have found a significant number of loose and broken arms, which was not the case. In addition, the postlarvae found in the plankton were consistently in a more advanced state than the larvae with a metamorphosed body that were still attached to posterolateral arms. The former featured arm spines, which were hooked at these early stages, while these spines were not observed in metamorphic ophioplutei (compare Figs. $1 \& 2$ ). Davoult (1989) also commented on the likelihood that this species metamorphoses completely while in the water column. In line with this, we would not expect to see a significant substratum selection in this species before settling to the bottom.

The study of planktonic states showed a main reproductive period in spring-early summer. However, a few larvae were also present in autumn and winter, indicating that small spawning events do occur during these seasons. We detected a clear peak of postlarvae centered in June. These results are consistent with juvenile abundance on the benthos and confirm the occurrence of a main recruitment event in late springearly summer. In no other season was there a clear presence of juveniles on sponges in this area. The data from the size histograms of recruits also indicated a main cohort arrival during June, and the growth of recruits afterwards. However, this did not preclude small numbers of new recruits arriving from July to October, as a few juveniles of the smallest size classes appeared in the samples (Fig. 9). These findings contrast with the reproductive periodicities identified for this species in other zones. Davoult (1989) and Davoult et al. (1990) reported 4 recruitment episodes in Atlantic populations of this species (February, April, June, and September, the latter being the most intense). Pedrotti (1993) reported the presence of larvae of Ophiothrix fragilis in plankton samples from the French Mediterranean in late spring and autumn.

The number of recruits was highest during June, then dropped quickly after settlement ceased, densities being reduced by more than 1 order of magnitude during July. By the first half of September, the abundances had undergone a ca 100-fold reduction with respect to the maximal figures (Fig. 10). We were not able to distinguish mortality from migration to other substrata, but high post-settlement mortality, of the same order or even higher than mortality during the planktonic stages, seems to occur in many benthic invertebrates (Thorson 1966, Hunt \& Scheibling 1997, López et al. 1998).

Our results point to an intense colonization of benthic substrata from the water column during June. High numbers of brittle stars reached the benthos, and colonization was significantly reduced by roof-type structures. This initial colonization was probably nonselective, judging from the poor (if any) swimming capabilities of postlarvae, which would 'rain' massively onto the substratum. Afterwards, however, the juveniles selected certain substrata, possibly through lateral movements. By the first half of July, once they had had time to resituate, there were significant differences in recruit densities in some sponge species with respect to those on the adjacent algal turf. However, the distribution analysis in June 1999, shortly after the recruitment peak, showed a weaker pattern of association (not significant at $p=0.05$ ) with the preferred species, indicating that this association was not yet established at the time of settlement.

Three 'preferred' species were identified among the 9 species studied. Other than the encrusting morphology (also shared by non-preferred forms), no common characteristic that might account for this preference can be put forward at present. In addition, 1 species showed a negative association (Corticium candelasbrum). Clearly, these patterns could be due to differential mortality on some substrata, rather than active migration. Although the relative contribution of the former could not be quantified, 2 clues made us believe that lateral colonization played an important role. First, there was a higher abundance of recruits at the periphery of one of the preferred sponges at the beginning of July, when migration should have been under way (Fig. 12). Second, we observed high recolonization rates in sponges periodically cleared of recruits during July, when postlarvae were very scarce in the plankton (Fig. 13). The dispersion of juveniles through resuspension into the water column may have contributed to the rates of recolonization observed. Resuspension and drifting following settlement is a significant factor in some invertebrates (Martel \& Chia 1991, Armonies 1994), and has been recently demonstrated in ophiuroids (Hendler et al. 1999a).

Field studies suggest, therefore, substratum selection by juveniles during the early post-settlement period. Experimental work is needed to provide evidence as to which stimuli can cue this selection. Physical cues such as water flow may influence substratum selection by brittle stars, which are known to be rheophilic (Broom 1975, Warner \& Woodley 1975). The nutritional condition affects the activity of sea urchins and sea stars (Harrold \& Reed 1985, McClintock \& Lawrence 1985) and this may prove important in brittle stars, too. On the 
other hand, chemical cues may trigger the associations found. As pointed out by Sloan \& Campbell (1982), among all the echinoderm classes, ophiuroids have the greatest potential for chemoreception studies. It is likely that the juvenile brittle stars respond to a combination of physical and biological cues.

The nature of the association between Ophiothrix fragilis and some sponge species cannot be unambiguosly established at present. The association may be related to feeding, defence, or both. We do have some evidence for a trophic relationship. When recruits were found on sponges with discrete inhalant fields (such as Phorbas tenacior), they were almost always lying on the inhalant fields, rather than on the other areas of the sponge. The juveniles are found with arms flat on the sponge, and the same is true for larger specimens hiding near the sponges and projecting their arms over the sponges, contrasting with the arm-raised posture of individuals in crevices and in aggregations (Broom 1975). This predominantly suspension-feeding ophiuroid captures particles by direct interception by raising its arms above the substratum (Warner 1971, Warner \& Woodley 1975, Davoult \& Gounin 1995, Allen 1998). We suggest that small juveniles with short arms cannot capture food efficiently, and that they rely on the feeding currents generated by sponges to increase the rate of contact with particles. These recruits would therefore act as commensals of sponges, although this relationship may also be mutualistic, as brittle stars can clean the inhalant surfaces of particles too large to enter through the sponge ostia (Hendler 1984). Some recruits are also found in the turf community, indicating that the association with sponges is not obligate. The benefits may lie in increased growth rates as a result of a trophic association.

Defence might be an alternative explanation for the associations found. The distribution of juvenile brittle stars is determined in some instances by the presence of refuge substrata where they can hide (Hendler \& Littman 1986, Steward \& Maldenov 1997). In our study, the juveniles adopted an exposed mode of existence on the encrusting sponges, so it seems unlikely that they were seeking protection unless, as Hendler (1984) suggested, toxic substances produced by sponges protect the associated juvenile brittle stars. However, according to Uriz et al. (1992) there are toxic and non-toxic sponges among the preferred species, and the same is true for the non-preferred sponges. All the species studied have smooth surfaces on which the juveniles are exposed, and in both preferred and nonpreferred sponges we can find species whose colour conceals the presence of the recruits, and other species on which they are clearly visible. In any case, the brittle stars leave the sponge surfaces as soon as they grow over $1 \mathrm{~mm}$ in disk diameter and seek refuge in interstices, which suggests a predation pressure at this size, perhaps mediated by fish that disregard smaller individuals. The potentially defensive role of the association of juvenile brittle stars with sponges, although it cannot be ruled out at present, awaits further experimental demonstration.

Association of adult brittle stars with sponges and other members of the epifauna and flora seems widespread in the Mediterranean and other seas (Zavodnik 1976, Hendler 1984, Koukouras et al. 1996), but recruitment of newly settled juveniles on sponges has only been noted sporadically. Zavodnik (1976) reports hundreds of juvenile Ophiothrix quinquemaculata on the ramified Mediterranean sponge Axinella cannabina, while Koukouras et al. (1996) reported the presence of juvenile $O$. fragilis on the same species. Kunzmann (1996) commented on the role of Antarctic hexactinellids as harbouring juveniles of species (brittle stars, pycnogonids) that live as adults on other substrata. Hendler (1984) reports small $O$. lineata on the external surfaces of the cup-shaped sponge Callyspongia vaginalis, while bigger specimens were found inside (exhalant area). Some of these associations are explained by the scarcity of available substrata in soft bottoms, which is not the case in our rocky bottoms. In the area studied, $O$. fragilis does not form the dense aggregations (up to 2000 ind. $\mathrm{m}^{-2}$ ) found in the Ophiothrix beds on gravel bottoms in the Atlantic European shores (Warner 1971, Allain 1974, Warner \& Woodley 1975, Davoult et al. 1990). In the Mediterranean, a similar phenomenon has been described for $O$. quinquemaculata, which forms aggregations (although less dense, up to 90 ind. $\mathrm{m}^{-2}$ ) on muddy and detritic bottoms along French shores (Guille 1964). In both cases, the dynamics of the populations follow the same pattern: the juveniles recruit on the adults and live for some time on disks, arms and bursae of adults. Then, at sizes of about 2 to $3 \mathrm{~mm}$ they migrate to rocky patches and epifaunal clumps, where they live on species of the epifauna such as sponges or ascidians. Finally, adult brittle stars of sizes $>7 \mathrm{~mm}$ migrate again to contribute to the dense aggregates forming Ophiothrix beds. This pattern is quite different from that found in the present study. According to our observations, the recruits grow on the sponges until, at sizes of about $1 \mathrm{~mm}$ in disk diameter, they leave the sponge surfaces and hide in the holes, crevices and interstices of the rocky wall. They finally migrate to the undersides of boulders, where the larger brittle stars are found.

The population dynamics described here add to the known variety of adaptive life strategies shown by Ophiothricidae. A point in common seems to be that the food capturing abilities of juveniles are not sufficient and need to be enhanced by taking advantage of the adult aggregation (baffle effect, Warner 1979) or the fil- 
tering activities of other organisms (such as sponges). The exposed nature of the juvenile habitat contrasts with the hidden habitat of brittle stars $>1 \mathrm{~mm}$ in disk diameter, and possibly involves a cost in terms of mortality that may be offset by a more rapid development to sizes at which autonomous feeding is efficient.

Acknowledgements. S. de Caralt (University of Barcelona) helped with sample processing. C. Duarte (CEAB, Blanes) provided the plankton samples from the Bay of Blanes used for the quantification of ophiuroid larvae. S. Mariani (CEAB, Blanes) provided data from the epibenthic plankton in the area. This study was funded by the projects PB94-0015, AMB94-0746 and MAR98-1004 of the Spanish Interministerial Commission for Science and Technology (CICYT).

\section{LITERATURE CITED}

Abelson A, Denny M (1997) Settlement of marine organisms in flow. Annu Rev Ecol Syst 28:317-339

Allain JY (1974) Écologie des bancs d'Ophiothrix fragilis (Abildgaard) (Echinodermata, Ophiuroidea) dans le golfe Normanno-breton. Cah Biol Mar 15:255-273

Allen JR (1998) Suspension feeding in the brittle star Ophiothrix fragilis: efficiency of particle retention and implications for the use of encounter-rate models. Mar Biol 132: 383-390

Andre P, Duarte CM (1996) Zooplankton seasonality in Blanes Bay (northwestern Mediterranean). Publ Espec Inst Esp Oceanogr 2:47-54

Armonies W (1994) Drifting meio- and macrobenthic invertebrates on tidal flats in Koenigshafen: a review. Helgol Meeresunters 48:299-320

Broom DM (1975) Aggregation behaviour of the brittle star Ophiothrix fragilis. J Mar Biol Assoc UK 55:191-197

Butman CA (1987) Larval settlement of soft-sediment invertebrates: the spatial scales of pattern explained by active habitat selection and the emerging role of hydrodynamical processes. Oceanogr Mar Biol Annu Rev 25:113-165

Butman CA, Grassle JP, Webb CM (1988) Substrate choices made by marine larvae settling in still water and in a flume flow. Nature 333:771-773

Cameron RA, Schroeter SC (1980) Sea urchin recruitment: effect of substrate selection on juvenile distribution. Mar Ecol Prog Ser 2:243-247

Chia FS (1989) Differential larval settlement of benthic marine invertebrates. In: Ryland JS, Tyler PA (eds) Reproduction, genetics and distribution of marine organisms. Olsen \& Olsen, Fredensborg, p 3-12

Davoult $D$ (1989) Structure démographique et production de la population d'Ophiothrix fragilis (Abildgaard) du Détroit du Pas-de-Calais, France. Vie Mar 10:116-127

Davoult D, Gounin F (1995) Suspension-feeding activity of a dense Ophiothrix fragilis (Abildgaard) population at the water-sediment interface: time coupling of food availability and feeding behaviour of the species. Estuar Coast Shelf Sci 41:567-577

Davoult D, Gounin F, Richard A (1990) Dynamique et reproduction de la population d'Ophiothrix fragilis [Abildgaard) du détroit du Pas-de-Calais (Manche orientale). J Exp Mar Biol Ecol 138:201-216

Fenaux L, Pedrotti ML (1988) Metamorphose des larves d'Echinides en pleine eau. PSZN I: Mar Ecol 9:93-107

Gosselin LA, Qian PY (1997) Juvenile mortality in benthic invertebrates. Mar Ecol Prog Ser 146:265-282

Guille A (1964) Contribution a l'étude de la systématique et de l'écologie d'Ophiotrix quinquemaculata $d$. Ch. Vie Milieu 15:243-308

Harrold C, Reed DC (1985) Food availability, sea urchin grazing, and kelp forest community structure. Ecology 66 : 1160-1169

Harrold C, Lisin S, Light KH, Tudor S (1991) Isolating settlement from recruitment of sea urchins. J Exp Mar Biol Ecol $147: 81-94$

Hendler G (1984) The association of Ophiothrix lineata and Callyspongia vaginalis: a brittlestar-sponge cleaning symbiosis? PSZN I: Mar Ecol 5:9-27

Hendler G (1991) Echinodermata: Ophiuroidea. In: Giese AC, Pearse JS, Pearse VB (eds) Reproduction of marine invertebrates, Vol VI. Echinoderms and lophophorates. The Boxwood Press, Pacific Grove, p 355-509

Hendler G, Littman BS (1986) The ploys of sex: relationships among the mode of reproduction, body size and habitats of coral-reef brittlestars. Coral Reefs 5:31-42

Hendler G, Baldwin CC, Smith DG, Thacker CE (1999a) Planktonic dispersal of juvenile brittle stars (Echinodermata: Ophiuroidea) on a Caribbean reef. Bull Mar Sci 65: 283-288

Hendler G, Grygier MJ, Maldonado E, Denton J (1999b) Babysitting brittle stars: heterospecific symbiosis between ophiuroids (Echinodermata). Invertebr Biol 118:190-201

Hunt HL, Scheibling RE (1997) Role of early post-settlement mortality in recruitment of benthic marine invertebrates. Mar Ecol Prog Ser 155:269-301

Keegan BF (1974) The macrofauna of maerl substrates on the west coast of Ireland. Cah Biol Mar 15:513-530

Keough MJ, Downes BJ (1982) Recruitment of marine invertebrates: the role of active larval choices and early mortality. Oecologia 54:348-352

Koukouras A, Russo A, Voultsiadou-Koukoura E, Arvanitidis C. Stefanidou D (1996) Macrofauna associated with sponge species of different morfology. PSZN I: Mar Ecol $17: 569-582$

Kunzmann K (1996) Associated fauna of selected sponges (Hexactinellida and Demospongiae) from the Weddell Sea, Antarctica. Rep Polar Res 210:1-93

López S, Turon X, Montero E, Palacín C, Duarte CM, Tarjuelo I (1998) Larval abundance, recruitment and early mortality in Paracentrotus lividus (Echinoidea). Interannual variability and plankton-benthos coupling. Mar Ecol Prog Ser 172:239-251

Martel A, Chia FS (1991) Drifting and dispersal of small bivalves and gastropods with direct development. J Exp Mar Biol Ecol 150:131-147

McClintock JB (1987) Investigation on the relationships between invertebrate predation and biochemical composition, energy content, spicule armament and toxicity of benthic sponges at McMurdo Sound, Antarctica. Mar Biol 94:479-487

McClintock JB, Lawrence JM (1985) Size selectivity of the prey by Luidia clathrata (Say) (Echinodermata: Asteroidea): effect of nutritive condition and age. In: Keegan BF, O'Connor DBS (eds) Echinodermata. AA Balkema, Rotterdam, p 533-539

McClintock JB, Hopkins T, Marion K, Watts S, Schinner G (1993) Population structure, growth and reproductive biology of the gorgonocephalid brittlestar Asteropora annulata. Bull Mar Sci 52:925-936

Mladenov PV (1979) Unusual lecitotrophic development of the Caribbean brittlestar Ophiothrix oerstedi. Mar Biol 55 : $55-62$ 
Mortensen T (1977) Handbook of the echinoderms of the British Isles. W Backhuis, Rotterdam

Nagabhushanam AK, Colman JS (1959) Carrion-eating by ophiuroids. Nature 184:285

Osman RW, Whitlatch RB (1995) The influence of resident adults on recruitment: a comparison to settlement. J Exp Mar Biol Ecol 190:169-198

Patent DH (1970) Life history of the basket star, Gorgonocephalus eucnemis (Müller \& Troschel) (Echinodermata: Ophiuroidea). Ophelia 8:145-160

Pawlik JR (1992) Chemical ecology of the settlement of benthic marine invertebrates. Oceanogr Mar Biol Annu Rev 30:273-335

Pawlik JR, Chanas B, Toonen RJ, Fenical W (1995) Defenses of Caribbean sponges against predatory reef fish. 1 Chemical deterrency. Mar Ecol Prog Ser 127:183-194

Pedrotti ML (1993) Spatial and temporal distribution and recruitment of echinoderm larvae in the Ligurian sea. J Mar Biol Assoc UK 73:513-530

Rumrill SS (1990) Natural mortality of marine invertebrate Iarvae. Ophelia 32:163-198

Schoppe S, Werding B (1996) The boreholes of the sea urchin genus Echinometra (Echinodermata: Echinoidea: Echinometridae) as a microhabitat in tropical South America. PSZN I: Mar Ecol 17:181-186

Sloan NA (1982) Size structure of echinoderm populations associated with different coexisting coral species at Aldabra Atoll, Seychelles. Mar Biol 66:67-75

Sloan NA, Campbell AC (1982) Perception of food. In: Jangoux $M$, Lawrence JM (eds) Echinoderm nutrition. AA Balkema, Rotterdam, p 3-23

Stewart BG, Mladenov PV (1997) Population structure, growth and recruitment of the euryalinid brittle star Astrobrachion constrictum (Echinodermata: Ophiuroidea) in Doubtful Sound, Fiordland, New Zealand. Mar Biol 127: $687-697$

Strathmann RR (1978) Larval settlement in echinoderms. In: Chia FS, Rice ME (eds) Settlement and metamorphosis

Editorial responsibility: Otto Kinne (Editor),

Oldendorf/Luhe, Germany of marine invertebrate larvae. Elsevier, New York, p 235-246

Thorson G (1966) Some factors influencing the recruitment and establishment of marine benthic communities. Neth J Sea Res 3:267-293

Tortonese E (1965) Fauna d'Italia. Echinodermata. Edizioni Calderini, Bologna

Turner RL, Miller JE (1988) post-metamorphic recruitment and morphology of two sympatric brittlestars. In: Burke RD, Mladenov PV, Lambert P, Parsley RL (eds) Echinoderm biology. AA Balkema, Rotterdam, p 493-502

Turon X, Becerro MA, Uriz MJ, Llopis J (1996) Small-scale association measures in epibenthic communities as a clue for allelochemical interactions. Oecologia 108:351-360

Uriz MJ, Rosell D, Martin D (1992) Relationships of biological and taxonomic characteristics to chemically mediated bioactivity in Mediterranean littoral sponges. Mar Biol 113: 287-297

Von Ende CN (1993) Repeated-measures analysis: growth and other time-dependent measures. In: Scheiner SM, Gurevich J (eds) Design and analysis of ecological experiments. Chapman and Hall, New York, p 113-137

Wahl M, Hay ME (1995) Associational resistance and shared doom: effects of epibiosis on herbivory. Oecologia 102: 329-340

Warner GF (1971) On the ecology of a dense bed of the brittle star Ophiothrix fragilis. J Mar-Biol Assoc UK 51:267-282

Warner GF (1979) Aggregation in echinoderms. In: Larwood G, Rosen BR (eds) Biology and systematics of colonial organisms. Academic Press, London, p 375-396

Warner GF (1982) Food and feeding mechanisms: Ophiuroidea. In: Jangoux M, Lawrence JM (eds) Echinoderm nutrition. AA Balkema, Rotterdam, p 161-181

Warner GF, Woodley JD (1975) Suspension-feeding in the brittle star Ophiothrix fragilis. J Mar Biol Assoc UK 55: 199-210

Zavodnik D (1976) Adriatic echinoderms inhabiting benthic organisms. Thalassia Jugosl 12:375-380

Submitted: March 26, 1999; Accepted: December 21, 1999 Proofs received from author(s): June 16, 2000 